\title{
Expression and Localization of a Major Lysosomal Membrane Sialoglycoprotein (LGP107) in Plasma Membranes of Rat Osteoblasts and Osteocytes*
}

\author{
Akifumi Akamine ${ }^{1}$, Takayuki Tsukuba ${ }^{2}$, Ryusei Kimura ${ }^{1}$, Katsumasa Maeda ${ }^{1}$, \\ Yoshitaka TANAKA ${ }^{3}$, Keitaro KATO ${ }^{3}$ and Kenji YAMAMOTO ${ }^{2}$ \\ Department of Conservative Dentistry $\mathrm{I}^{1}$, and Department of Pharmacology ${ }^{2}$, Kyushu University Faculty of Dentistry, Fukuoka; \\ and Department of Physiological Chemistry ${ }^{3}$, Kyushu University Faculty of Pharmaceutical Sciences, Fukuoka, Japan
}

Received September 10, 1993

\begin{abstract}
Summary. The immunocytochemical localization of a major lysosomal membrane sialoglycoprotein with a molecular mass of $107 \mathrm{kDa}$, which was designated as LGP107, was investigated in osteoblast lineage cells involved in osteoclastic bone resorption using specific polyclonal antibody against LGP107. Osteoclastic bone resorption was induced by transplantation of parathyroid glands. In control experiments, no immunoreaction product for LGP107 was recognized in osteoblasts and osteocytes. Strong immunoreaction products for LGP107 occurred on the plasma membranes in the osteoblasts and osteocytes prior to the appearance of osteoclasts one day after transplantation of the parathyroid glands. Furthermore, two days after induction, strong diaminobenzidine reactions were also observed on the plasma membranes in the osteoblastic cells adjacent to the active osteoclasts.

These data suggest that LGP107 in osteoblastic cells and osteocytes may play an important role in cellrecognition and/or cell-adhesion, and that LGP107 may be involved in osteoblastic degradation of the osteoid as well as exposure of the bone surface.
\end{abstract}

Many reports have recently demonstrated that osteoblastic cells, which have been thought to be involved in only bone formation, play a crucial role in osteoclastic bone resorption. First, it is believed that there is a mechanism whereby osteoblastic cells participate directly in bone resorption, as in vitro studies have suggested that osteoblastic cells have receptors for, and directly respond to, PTH (parathormone) and $1 \alpha$, $25(\mathrm{OH})_{2} \mathrm{D}_{3}$, whereas osteoclasts do not (CHAMBERS,
1985). In addition, it was reported that osteoblastic cells produce pro-collagenase and the tissue plasminogen activator in vitro, the synthesis and secretion of which is enhanced by PTH (SAKAMOTO and SAKAMOTO, 1982; HAMILTON et al., 1984; PARTRIDGE et al., 1987). Furthermore, electron microscopic autoradiography in vivo has revealed that a major osseous target cell for PTH is of the osteoblast lineage, but not a differentiated osteoblast (RoulEAU et al., 1990). A second line of thought is that there is another mechanism whereby osteoblastic cells are involved in controlling the differentiation and activation of osteoclasts through cell to cell interaction. SUDA and his colleagues (1992) suggested that only certain types of cells of the osteoblast lineage have the capacity to support osteoclast differentiation and activation through direct cell to cell contact. OzAWA and his colleague's report (1990) of a fine structural and cytochemical study also agrees with SuDA et al. More recently, FULLER et al. (1991) reported that the osteoclast resorption-stimulating activity (ORSA) might be retained by glycoproteins of the osteoblastic cell surface, and the mobilization of ORSA might occur through neutral protease release by osteoblastic cells in response to bone-resorbing hormones. In these ways recent studies have shown that osteoblastic cells control osteoclastic bone resorption directly or indirectly; the precise mechanism remains unclear, however.

LGP107 is a major lysosomal membrane glycoprotein with an apparent molecular mass of $107 \mathrm{kDa}$

*This study was supported in part by a Grant-in-Aid for Scientific Research (03670896) from the Ministry of Education, Science and Culture, Japan. 
(YAmAMoto et al., 1980; OHsumi et al., 1983; Himeno et al., 1989; AKASAKI et al., 1990) and constitutes approximately $6 \%$ of the total lysosomal membrane protein. This protein possesses a large number of $\mathrm{N}$-linked heavily sialyated complex-type olygosaccharide chains and its sialic acid content comprises $25 \%$ of the total sialic of lysosomal membranes (AKASAKI et al., 1990). It has therefore been accepted that the protein could contribute to the protection of lysosomal membranes from attack by lysosomal enzymes (GRANGER et al., 1990), the regulation of fusion events including endosomes, phagosomes and the plasma membranes as well as lysosomes, and the maintenance of the acidic environment (FUKUDA, 1991). Recently, however, several reports indicate that LGP107 is present on the plasma membrane as well as the lysosomes. CARLSSON and FUKUDA (1992) showed that newly synthesized LGP molecules are directly transported into the lysosomes, and a minor part of LGP is targeted to the cell surface, indicating that LGP is sorted by two alternative pathways. In addition, LGP is recycled between the cell surface and the lyso- somes (LIPPINCOTT-SCHWARTZ and FAMBROUGH, 1986; FURUNO et al., 1989). In particular, LGP appears to be expressed in the plasma membranes when cells are activated. This notion is based on the finding that, the platelet is activated, LGP molecules are significantly translocated to the plasma membrane, while few are localized on the cell surface in a resting state (FEBbraio and Silverstain, 1990). More recently, we found that LGP107 was largely synthesized in active osteoclasts and rapidly translocated to the plasma membrane at the ruffled border (AKAMINE et al., 1993).

We therefore examined immunocytochemically the localization of LGP107 in osteoblast lineage cells using parathyroid gland transplantation, in order to clarify the role of LGP107 in osteoblast lineage cells involved in osteoclastic bone resorption.

\section{MATERIALS AND METHODS}

\section{Transplantation of parathyroid glands}

Induction of bone resorption was carried out accord-

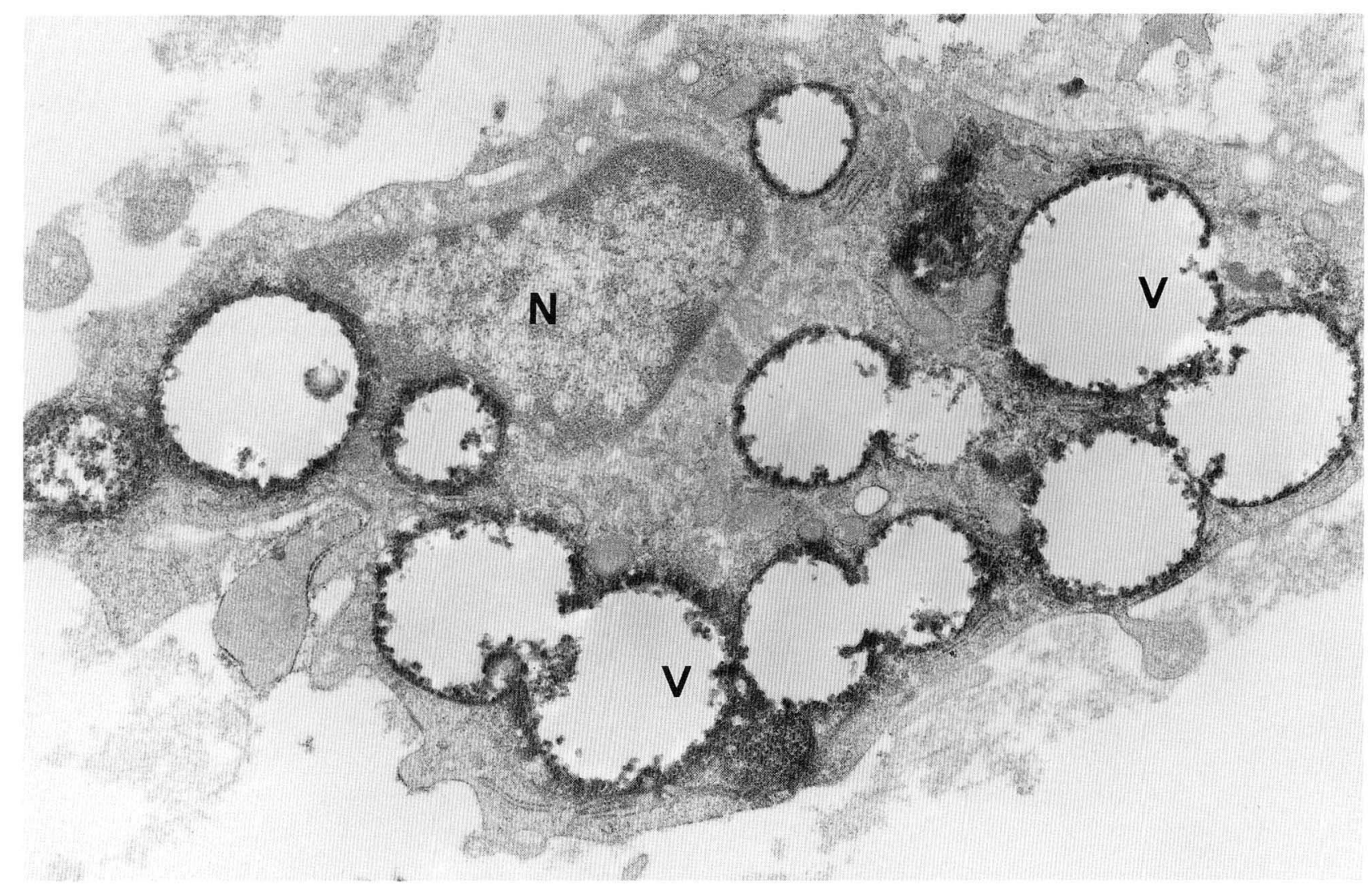

Fig. 1. Electron micrograph of a macrophage-like cell found in the preparation of rat calvaria. Calvaria of a rat 2 days after transplantation of the parathyroid glands in the subcutaneous tissues on the parietal bones was fixed and processed using peroxidase-diaminobenzidine labeling. The reaction products are found primarily in the endocytic vacuolar compartments. The plasma membrane is negative for LGP107. $N$ nucleus, $V$ vacuole. $\times 15,000$ 
ing to the method of BARNICOT (1948) with some modifications. The heads of 4 -week-old WKA rats were shaved and sterilized, the skin on the head cut and stripped. The parietal bones covered with thin connective tissues were exposed. Parathyroid glands prepared from another rat of the same strain amounting to about $300 \mathrm{~g}$ were inserted into the connective tissues on the parietal bones of both the right and left sides, while care was taken not to damage the periosteum. When the transplantation was finished, the skin was sutured with silk. On days 1 and 2, the transplanted rats were intracardially perfused with $3 \%$ paraformaldehyde and $0.5 \%$ glutaraldehyde in 0.1 $\mathrm{M}$ phosphate buffer, $\mathrm{pH} 7.4$ containing $0.05 \% \mathrm{CaCl}_{2}$ for $15 \mathrm{~min}$. The calvaria was immersed in the same fixative for $2 \mathrm{~h}$ at $4^{\circ} \mathrm{C}$. After fixation, the specimens were washed in $0.1 \mathrm{M}$ phosphate buffered saline (PBS) and then decalcified with 10\% EDTA containing $4 \%$ sucrose for 7 days at $4^{\circ} \mathrm{C}$. The decalcified specimens were cut into $100 \mu \mathrm{m}$-thick sections with a Microslicer. The sections were treated for $1 \mathrm{~h}$ in $0.5 \%$ dimethylsulfoxide, $8 \%$ sucrose in $0.1 \mathrm{M}$ PBS. The specimens were treated with $0.3 \% \mathrm{H}_{2} \mathrm{O}_{2}$ in $0.1 \mathrm{M}$ PBS to inhibit endogenous peroxidase and then incubated with the primary antibody $(50 \mu \mathrm{g} / \mathrm{ml})$ for 2 days at $4^{\circ} \mathrm{C}$. After washing in PBS, the specimens were stained using the avidin-biotin-peroxidase complex $(\mathrm{ABC})$ kit (Vector Laboratories, Burlingame, CA). The stained specimens were incubated in $0.5 \mathrm{mM}$ $3.3^{\prime}$-diaminobenzidine tetrahydrochloride and $0.005 \%$ $\mathrm{H}_{2} \mathrm{O}_{2}$ in $0.05 \mathrm{M}$ Tris- $\mathrm{HCl}$ buffer, $\mathrm{pH}$ 7.6. Control specimens were treated in the same way except that the primary antibody was omitted or replaced by a non-immunized rabbit IgG. For immunoelectron microscopy, the specimens were postfixed for $1 \mathrm{~h}$ with $1 \%$ $\mathrm{OsO}_{4}$ in $0.1 \mathrm{M}$ phosphate buffer, $\mathrm{pH}$ 7.4, dehydrated through graded ethanol and embedded in Epon 812. Ultrathin sections were examined with or without uranyl stain in a H-7000 electron microscope (Hitachi, Tokyo, Japan).

\section{Antibodies}

LGP107 was purified from rat liver by specific affinity chromatography by the methods of YАMAMOTO et al. (1980) and OHsumi et al. (1983) with some modifications. Antiserum against the purified LGP107 was prepared from a white rabbit injected with an emulsified mixture of an equal volume of Freund's complete adjuvant from the antiserum. Specific LGP107 antibodies were purified by affinity chromatography on LGP107.

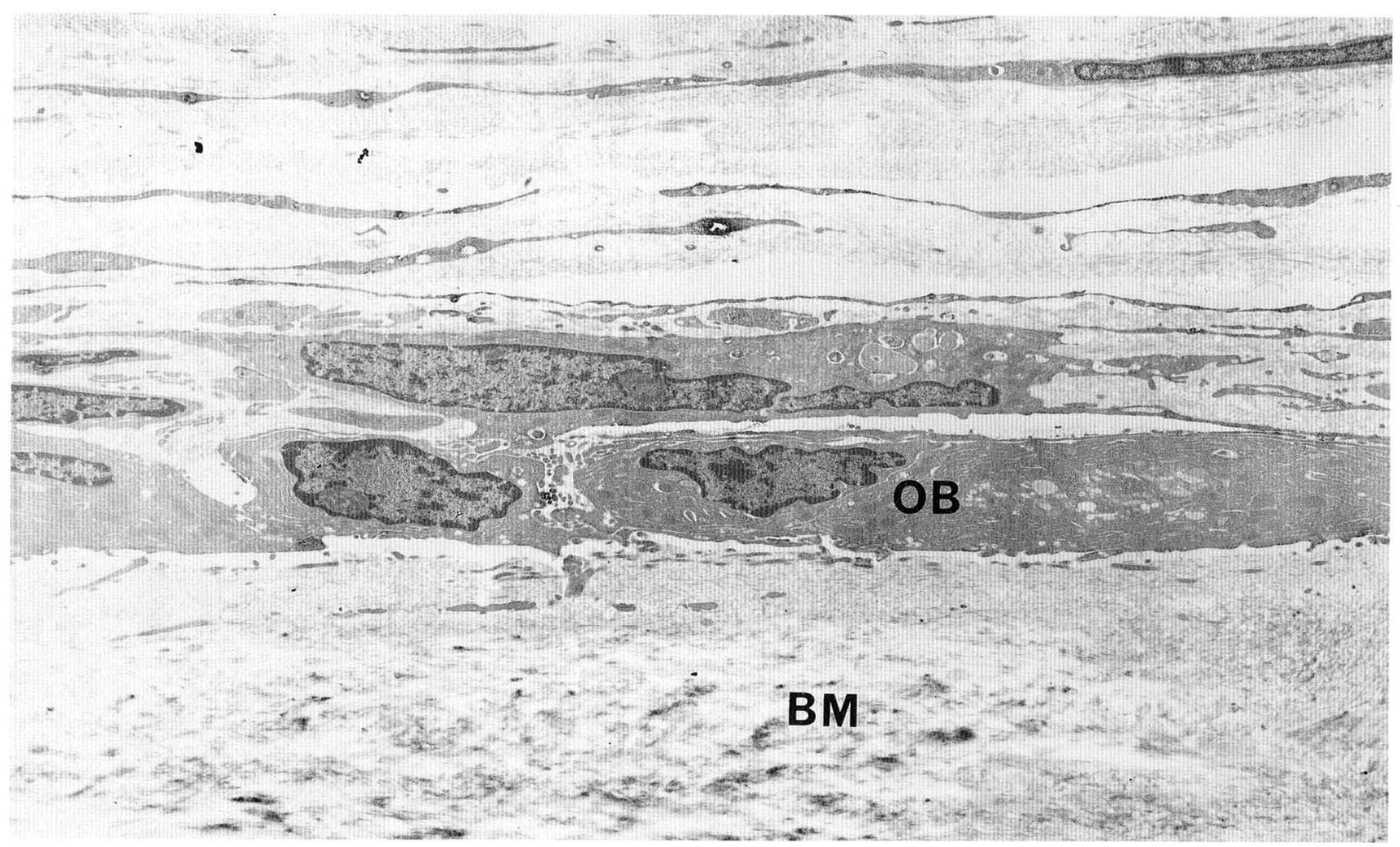

Fig. 2. Electron micrograph of flattened osteoblasts $(O B)$ on the bone surface in a non-transplanted control animal. These cells have no immunoreaction products for LGP107. BM bone matrix. $\times 4,700$ 


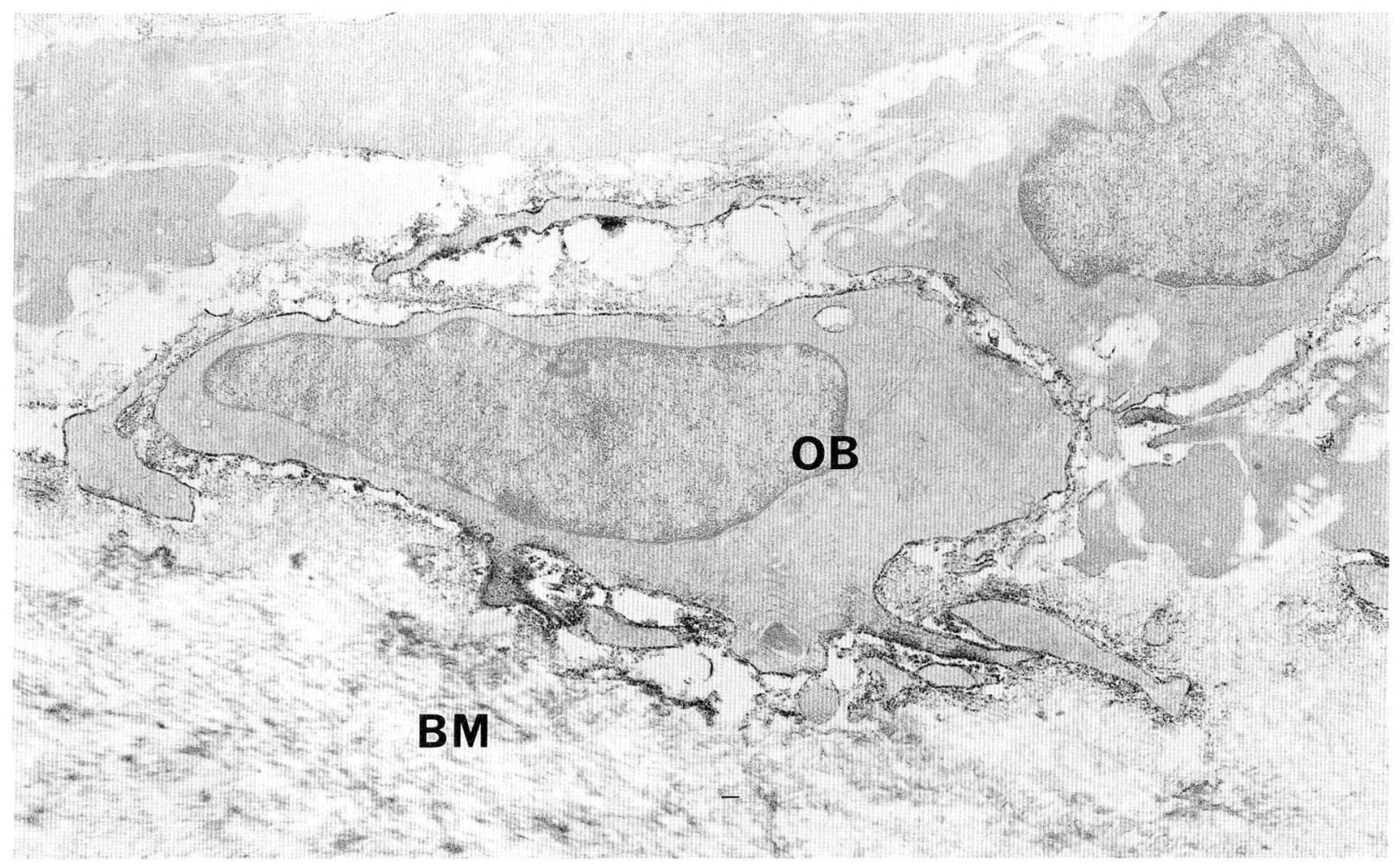

Fig. 3. Electron micrograph of osteoblasts $(O B)$, one day after transplantation. Cells tend to become rounded and possess better-developed organelles. Note the thin cytoplasmic processes. Intense immunoreactivity for LGP107 is present on the plasma membrane and bone surface. $B M$ bone matrix. $\times 10,000$

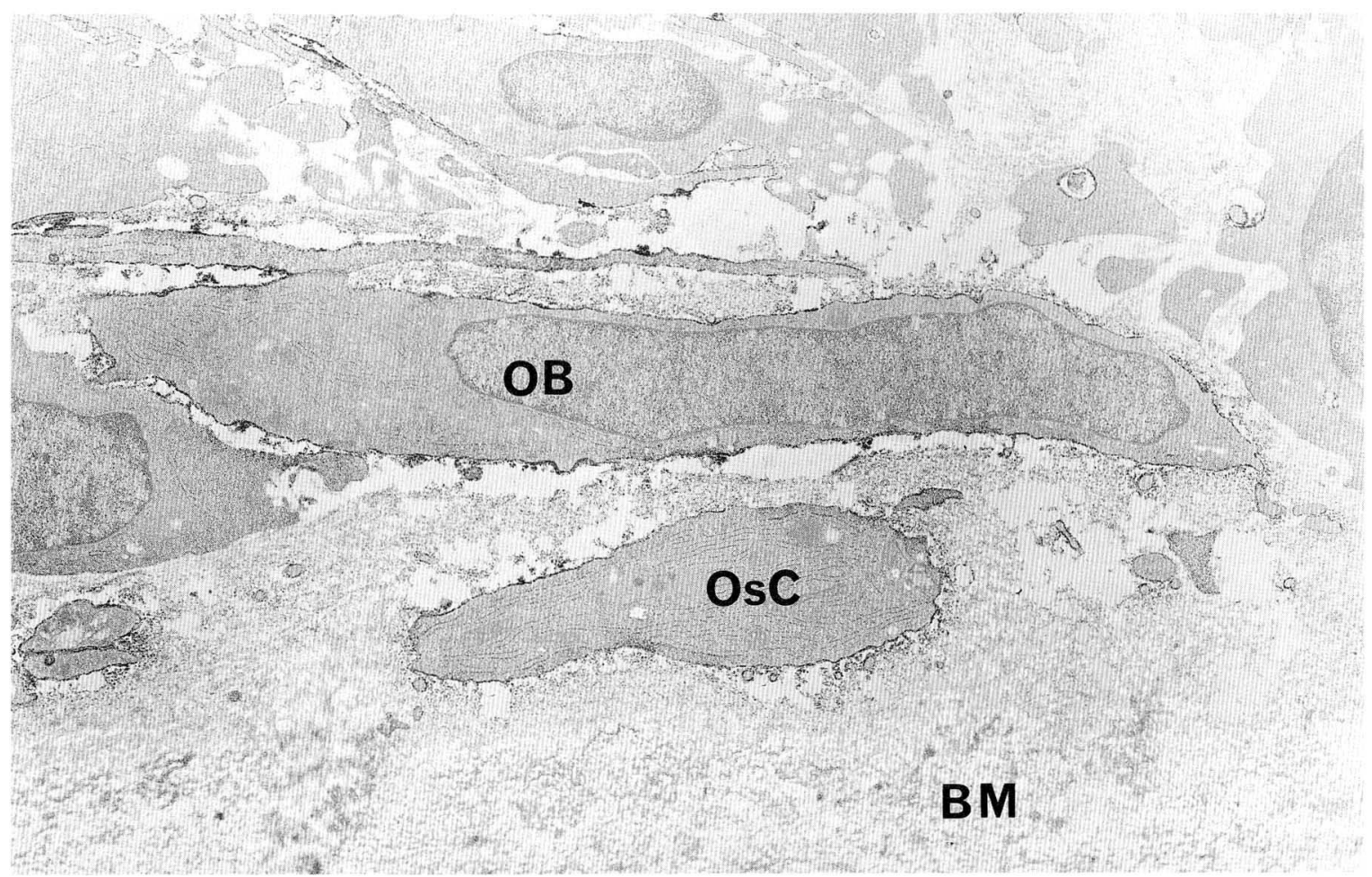

Fig. 4. Electron micrograph of osteocytes $(O S C)$ and osteoblasts $(O B)$, one day after induction. Osteocyte embedded in the bone matrix $(B M)$ is also positive for LGP107. $\times 9,000$ 


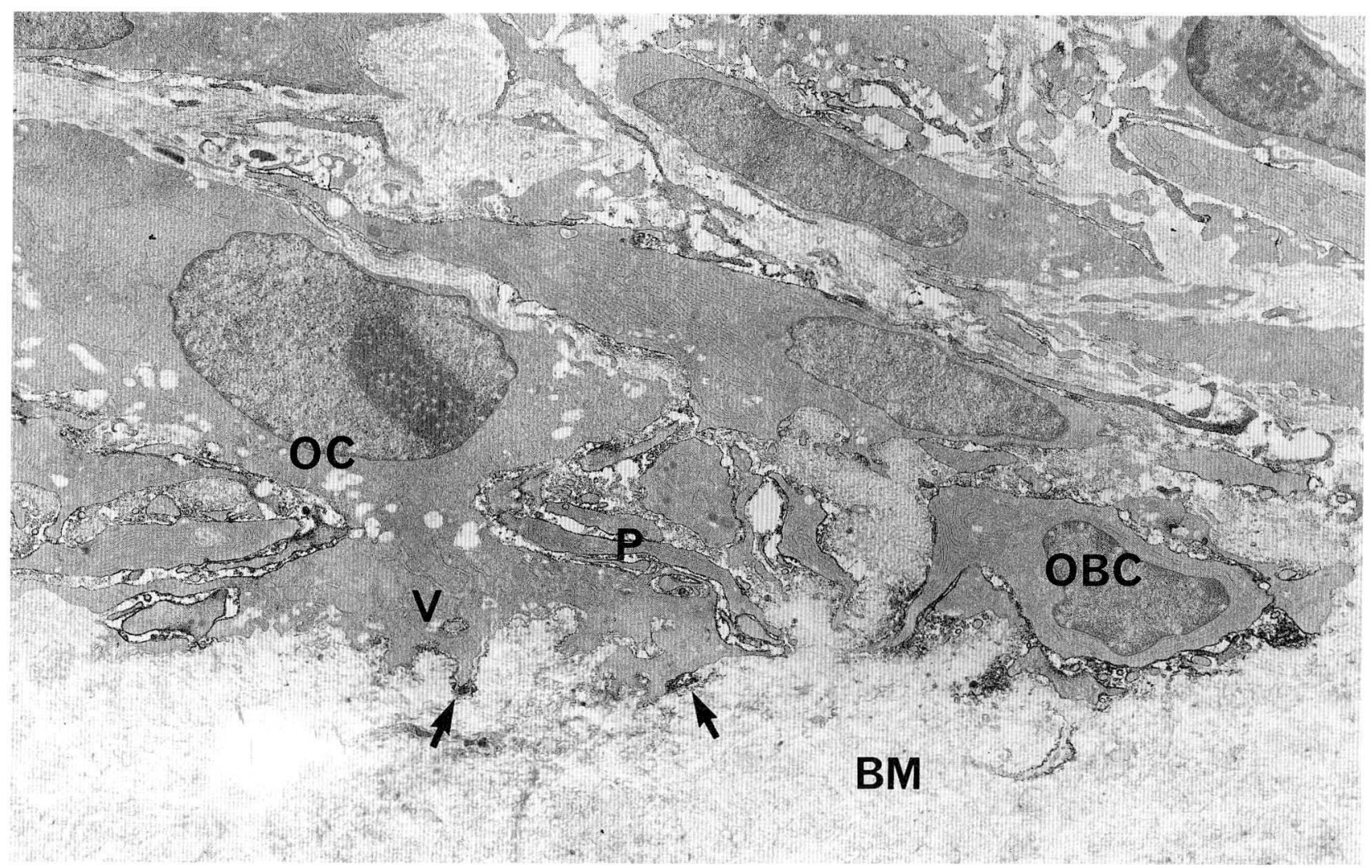

Fig. 5. Electron micrograph of an osteoblastic cell $(O B C)$ and an immature osteoclast $(O C)$, two days after transplantation. Immature osteoclast is seen on the bone surface. The immunoreaction products for LGP107 (arrows) are rarely seen on the front of the bone matrix $(B M)$ and vacuole-like structure $(V)$. Reaction staining is also localized on the plasma membranes of both immature osteoclast and osteoblastic cell processes $(P)$. Intense reaction is seen on the plasma membrane in the neighboring osteoblastic cells $(O B C) . \times 6,000$

\section{RESULTS}

In order to confirm the specificity and immunoreactivity of the antibodies used, immunocytochemical localization of LGP107 was first examined in various cell types other than osteoblastic cells. In macrophagelike cells found in the preparation of rat calvaria, the labeling for this antigen was found primarily in the endocytic vacuolar compartments with a variety of shapes and sizes, but not in plasma membranes (Fig. 1). This result was consistent with the previous observation by FURUNO et al. (1989), who demonstrated the immunocytochemical localization of this glycoprotein within lysosomes of primary cultured rat hepatocytes. We then proceeded to localize LGP107 in rat osteoblast lineage cells involved in osteoclastic bone resorption.

The ectocranial periosteal surface of the parietal bone was covered with a single layer of the flattened osteoblasts. In control specimens without transplan- tation, both osteoblasts and osteocytes were negative for the immunoreaction for LGP107 (Fig. 2).

One day after transplantation, the flattened osteoblasts were disordered in arrangement, and became cuboidal or elongated in shape. Strong immunoreaction products for LGP107 occurred on the plasma membranes in the cuboidal osteoblasts as shown in Figure 3. Simultaneously, immunolabelings for LGP107 on the plasma membranes of osteocytes located near the bone surface were observed as well as the elongated osteoblasts (Fig. 4). In contrast, no LGP107 reaction-products were recognized in deeply buried osteocytes (data not shown).

Two days after induction, osteoclast precursor cells and mature osteoclasts appeared on the bone surface. Figure 5 shows LGP107 immunoreactions in an immature osteoclast and osteoblasic cells. LGP107 immunoreaction products occurred on the plasma membranes and cytoplasmic processes in the osteoblastic cells. On the other hand, LGP107 immunostainings were only recognized on ill-developed 


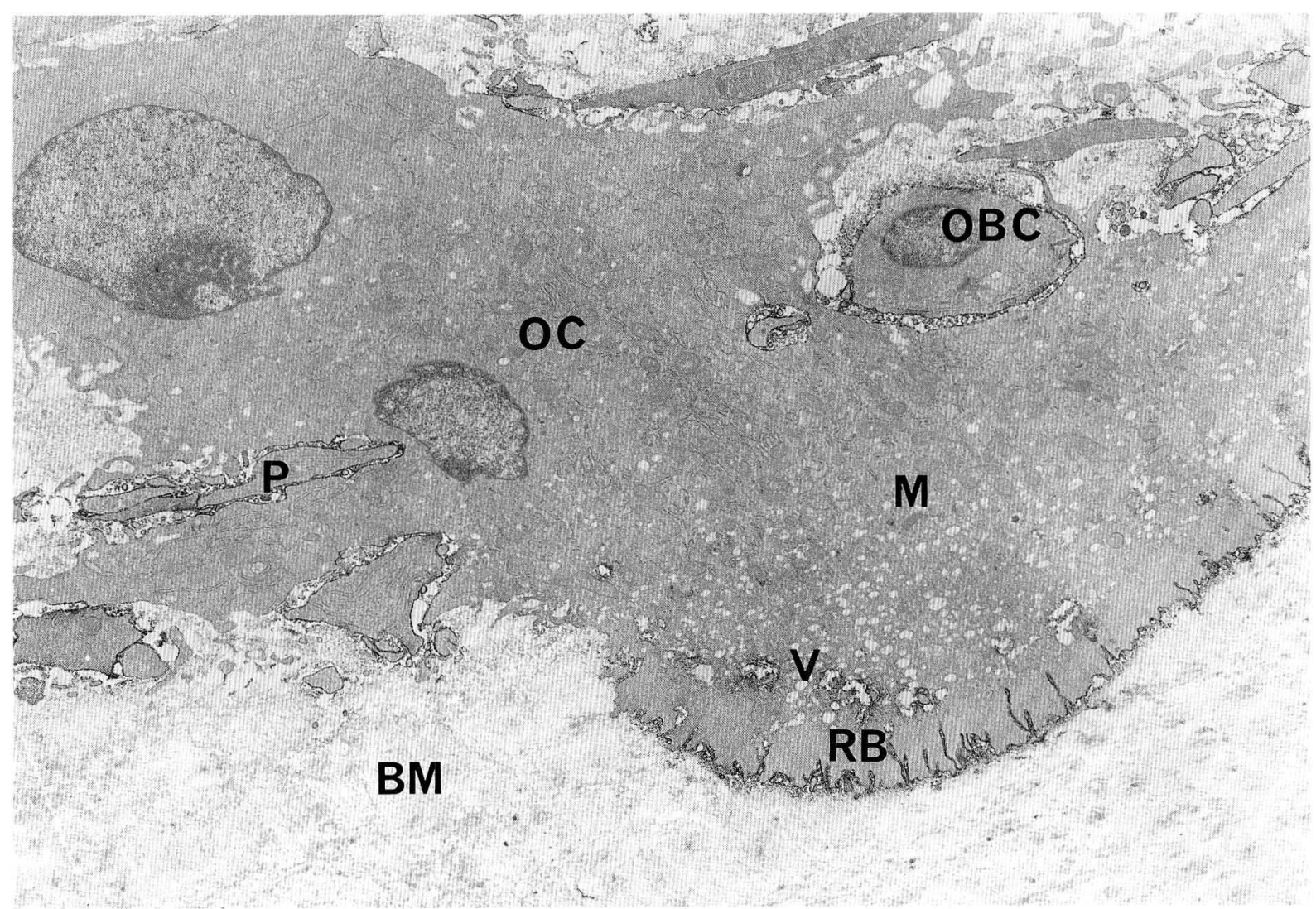

Fig. 6. Electron micrograph of a multinuclear mature osteoclast $(O C)$, two days after transplantation. The active osteoclast possesses a prominent ruffled border $(R B)$, many mitochondria $(M)$ and vacuoles $(V)$, as well as scattered cisterns of rough endoplasmic reticulum. Immunolabelings for LGP107 are detected in the ruffled border and vacuoles. Intensely positive reactions for LGP107 are present on the plasma membrane in the osteoblastic cell $(O B C)$ and its cytoplasmic processes $(P)$ in direct contact with the active osteoclast. $B M$ bone matrix. $\times 6,000$

ruffled border membranes in the immature osteoclast and the contact regions for osteoblastic cell processes. When the bone resorption proceeded, multinuclear mature osteoclasts which had prominent ruffled borders, many mitochondria and vacuoles and scattered cisterns of the rough-surfaced endoplasmic reticulum were observed on the bone surface. Immunolabelings for LGP107 in the active osteoclast were detected at the ruffled border membranes and a variety of vacuoles. More interestingly, strong immunoreactions were seen in the plasma membrane of the osteoblastic cells and their cytoplasmic processes which were in contact with the active osteoclasts (Fig. 6).

\section{DISCUSSION}

The present study is the first report to demonstrate a cell surface expression of LGP107 on osteoblastic cells. We speculate that there are two possible roles of LGP107 expressed in osteoblastic cells. One is that LGP107 may play an important role in cell-recognition and/or cell-adhesion. It is suggested that the recognition mechanism is influenced by various growth factors associated with the plasma membranes, when osteoclastic progenitor cells are contacted and recognized by osteoblastic stromal cells that induce their proliferation and maturation (TAVASSLI and HARDY, 1990). Interestingly, a recent report showed that osteoclast resorption-stimulating activity is associated with the osteoblastic cell surface, implying that the glycoproteins on the plasma membranes play a critical role in extracellular interaction by cell to cell contact (FULLER et al., 1991). It is likely that the glycoproteins on the cell surface are responsible for the activation and cell maturation between osteoclasts and osteoblastic cells. In fact, the lysosomal membrane glycoproteins family contains intracellu- 
lar antigens such as CD63, a blood platelet activation marker (METZELAAR et al., 1991). Therefore, it is conceivable that LGP107 also participates in the cell to cell recognition.

The second possibility is that LGP107 may be involved in osteoblastic degradation of the osteoid and exposure of the bone surface. Although the bone surface is covered by osteoblasts, PTH changes the shape of the osteoblasts (RODAN and MARTIN, 1981). The osteoblasts degrade the osteoid and expose the bone surface, resulting in attracting osteoclast precursors by releasing collagen and osteocalcin (KAHN and PARTRIDGE, 1987). In this process, LGP107 may be expressed on the plasma membranes in the osteoblasts. If so, lysosomal enzymes may be released more efficiently for the degradation of bone organic matrix. Indeed, similar results have been reported where embryonal carcinoma cells express LGP on the surface in order to invade the extracellular matrix for metastasis (AMOS and LOTAN, 1990). However, it is not clear why osteoblastic cells are expressed on the whole cell surface, although active osteoclasts express LGP107 on ruffled border membranes (Fig. 6) (AKAMINE et al., 1993). The LGP107 immunoreaction was also recognized on the plasma membranes in excavated osteocytes as well as osteoblastic cells (Figs. 4, 5). We have also observed that deeply buried osteocytes possess no LGP107 reaction on the cell surface (data not shown). Conversely, our results suggest that osteocytes may revert to osteoblastic cells, as reported by RASMUSSEN and BORDIER (1974). Taken together, LGP107 in osteocytes may also play the same role as in osteoblastic cells.

The immunoreaction for LGP107 was observed on the endocytic vacuolar compartments in macrophagelike cells, but not in the primary lysosomes in osteoblasts and osteoclasts. The reason is not precisely known at present. It is likely that LGP107 is transported through primary lysosomes quickly and concentrated within secondary lysosomes, and that its concentration is too low to be detected immunohistochemically. This result is consistent with the report by BARON et al. (1985), who mentioned that the immunolabeling for a 100-KD lysosomal membrane protein could not be detected in the primary lysosomes of osteoclasts.

In summary, LGP107 is expressed on the plasma membranes in both the osteoblastic cells and osteocytes. LGP107 in osteocytes and osteoblastic cells may play a critical role in the bone resorption process.

Acknowledgments. We thank Ms. Yumiko TANIZAKI for typing the manuscript.

\section{REFERENCES}

Akamine, A., T. Tsukuba, R. Kimura, K. Maeda, Y. TANAKA, K. Kato and K. Yамамото: Increased synthesis and specific localization of a major lysosomal membrane sialoglycoprotein (LGP107) at the ruffled border membrane of active osteoclasts. Histochemistry 100: 101-108 (1993).

AKasaki, K., Y. Yamaguchi, M. Ohta, F. MatsuUra, K. Furuno and H. TsuJI: Purification and characterization of a major glycoprotein of a glycoprotein in rat liver lysosomal membrane. Chem. Pharm. Bull. 38: 2766-2770 (1990).

Amos, B. and R. Lotan: Modulation of lysosomal-associated membrane glycoproteins during retinoic acidinduced embryonal carcinoma cell differentiation. J. Biol. Chem. 265: 19192-19198 (1990).

BARnicot, N. A.: The local action of the parathyroid and other tissues on bone in intracerebral grafts. J. Anat. 82: 233-248 (1948).

Baron, R., L. NefF, D. Louvard and P. J. Courtoy: Cell-mediated extracellular acidification and bone resorption: Evidence for a Low $\mathrm{pH}$ in resorbing lacunae and localization of a $100-\mathrm{KD}$ lysosomal membrane protein at the osteoclast ruffled border. J. Cell Biol. 101: 2210-2222 (1985).

Carlsson, S. R. and M. Fukuda: The lysosomal membrane glycoprotein lamp-1 is transported to lysosomes by two alternative pathways. Arch. Biochem. Biophys. 296: 630-639 (1992).

Chambers, T. J.: The pathobiology of the osteoclast. J. Clin. Pathol. 38: 241-252 (1985).

Febbraio, M. and R. L. Silverstein: Identification and characterization of LAMP-1 as an activation-dependent platelet surface glycoprotein. J. Biol. Chem. 265: 1853118537 (1990).

FuKUdA, M.: Lysosomal membrane glycoproteins. Structure, biosynthesis, and intracellular trafficking. J. Biol. Chem. 266: 21327-21330 (1991).

Fuller, K., A. C. Gallagher and T. J. Chambers: Osteoclast resorption-stimulating activity is associated with the osteoblast cell surface and/or the extracellular matrix. Biochem. Biophys. Res. Comm. 181: 67-73 (1991).

Furuno, K., T. Ishikawa, K. Akasaki, S. Yano, Y. TanaKa, Y. Yamaguchi, H. TsuJi, M. Himeno and $\mathbf{K}$. KAT0: Morphological localization of a major lysosomal membrane glycoprotein in the endocytic membrane system. J. Biochem. 106: 708-716 (1989).

Granger, B. L., S. A. Gleen, C. A. Gabel, C. L. Howe, I. Mellman and A. Helenius: Characterization of cloning of lgp 110 a lysosomal membrane glycoprotein from mouse and rat cells. J. Biol. Chem. 265: 1203612043 (1990).

Hamilton, J. A., S. R. Lingelbach, N. C. Partridge and T. J. MARTIN: Stimulation of plasminogen activator in osteoblast-like cells by bone-resorbing hormones. Biochem. Biophys. Res. Comm. 122: 230-236 (1984). 
Himeno, M., Y. Noguchi, H. Sasaki, Y. Tanaka, K. Furuno, A. Kono, Y. SaKaki and K. Kato: Isolation and sequencing of a cDNA clone encoding $107-\mathrm{kDa}$ sialoglycoprotein in rat lysosomal membranes. FEBS Lett. 244: 351-356 (1989).

Kahn, A. J. and N. C. Partridge: New concepts in bone remodeling; an expanding role for the osteoblast. Amer. J. Otolaryngol. 8: 258-264 (1987).

LippincotT-Schwartz, J. and D. M. Fambrough : Lysosomal membrane dynamics: Structure and interorganellar movement of a major lysosomal membrane glycoprotein. J. Cell Biol. 102: 1593-1605 (1986).

Metzelaar, M. J., P. L. J. WiJngaARd, P. J. Peters, J. J. Sixma, H. K. Nieuwenhuis and H. C. Clevers: CD63 antigen, A novel lysosomal membrane glycoprotein, cloned by a screening procedure for intracellular antigens in eukaryotic cells. J. Biol. Chem. 266: 3239-3245 (1991).

OHSUmi, Y., T. IshiKaWA and K. KATo: A rapid and simplified method for the preparation of lysosomal membranes from rat liver. J. Biochem. 93: 547-556 (1983).

Ozawa, H., M. Irie, H. NaKamura and S. EJIRI: Autoradiographic, fine structural and cytochemical study of relationship between osteoclastic and osteoblastic cells in bone remodeling; In: (ed. by) C. CHRISTIANSEN and K. OVERGOARD: Osteoporosis 19903 (Third international symposium on osteoporosis, Copenhagen, Denmark 1420, Oct. 1990). Handelstrykkeriet Aalborg Aps, Aalborg, Denmark, 1990 (p. 2096-2101).

Partridge, N. C., J. J. Jeffrey, L. S. Ehlich, S. L. Teitelbau M, H. G. Fliszar, H. G. Welgus and A. J. KAHN: Hormonal regulation of the production of collagenase and collagenase inhibitor activity by rat osteogenic sarcoma cells. Endocrinology 120: 1956-1962 (1987).

RASmussen, H. and P. Bordier: In the physiological and cellular basis of metabolic bone disease. Wiliams and Wilkins C., New York, 43-51 (1974).
Rodan, G. A. and T. J. Martin : Role of osteoblasts in hormonal control of bone resorption-a hypothesis. Calcif. Tiss. Int. 33: 349-351 (1981).

Rouleau, M. F., J. Mitchell and D. Goltzman : Characterization of the major parathyroid hormone target cell in the endostal metaphysis of rat long bones. J. Bone Miner. Red. 5: 1043-1053 (1990).

Sakamoto, S. and M. Sakamoto: Biochemical and immunohistochemical studies on collagenase in resorbing bone in tissue culture; A novel hypothesis for the mechanism of bone resorption. J. Periodont. Res. 17: 523-526 (1982).

Suda, T., N. Takahashi and T. J. Martin: Modulation of osteoclast differentiation. Endocr. Rev. 13: 66-80 (1992).

Tavassli, M. and C. L. Hardy : Molecular basis of homing of intravenously transplanted stem cells to the marrow. Blood 76: 1059-1070 (1990).

YAMAMOTO, K., Y. IKEHARA, S. KAWAMOTO and K. KATO: Characterization of enzymes and glycoproteins in rat liver lysosomal membranes. J. Biochem. 87: 237-248 (1980).

\author{
Dr. Akifumi Akamine \\ Department of Conservative Dentistry I \\ Faculty of Dentistry \\ Kyushu University \\ 3-1-1 Maidashi, Higashi-ku \\ Fukuoka, 812 Japan \\ 赤峰 昭文 \\ 812 福岡市東区馬出 3-1-1 \\ 九州大学歯学部 \\ 歯科保存学第一講座
}

